Advances in Gene Technology: The Genome and Beyond -

Structural Biology for Medicine (Proceedings of the 2002 Miami

Nature Biotechnology Winter Symposium)

TheScientificWorld 2002, 2(S2), 11-12

ISSN 1532-2246; DOI 10.1100/tsw.2002.6

\title{
MOUSE GENOME INFORMATICS: MAPPING/HOMOLOGY DATA
}

\author{
D. Bradt, C.J. Bult, J.A. Blake, J.A. Kadin, J.E. Richardson, J.T. Eppig, and the Mouse Genome \\ Informatics Staff \\ The Jackson Laboratory, Bar Harbor, ME 04609 \\ http://www.informatics.jax.org
}

INTRODUCTION. The Mouse Genome Informatics Web site at The Jackson Laboratory provides access to primary data and consensus representations of genetic, expression, phenotypic, and genomic information about the laboratory mouse[1,2,3]. Among many important aspects of this information are the mouse genome mapping data and mammalian comparative mapping data in The Mouse Genome Database (MGD).

METHOD. Mouse mapping data in MGD includes curated reports, primary research data from scientific publications, electronically submitted data, and data downloads from major genome centers. Genetic and physical mapping information, including summary haplotypes, are provided with recombination statistics and associated references. Genetic linkage maps derived from MGD consensus map positions, chromosome committee reports and various mapping panels can be selectively and flexibly generated and graphically displayed. Maps can be customized to contain selected subsets of mouse genetic markers and to display known homologs of any of the mammalian species for which MGD contains comparative mapping information[4].

MGD currently provides a scientifically curated data set of comparative mapping information for a select group of mammalian species, predominantly mouse, human, and rat. The availability of the whole genomic sequence for human and mouse (and soon, rat) has shifted the emphasis of data curation from literature-derived to curator-analyzed electronic-derived data. MGD has developed a set of criteria that support the assertions of homology to aid users in evaluating these annotations. In addition to providing homology data with supporting evidence and references, MGD provides graphical tools to view genome-wide comparative mapping data. Oxford grid displays graphically show chromosome-to-chromosome comparisons indicating the speciesspecific distribution of homologous genes. MGD also provides chromosomal comparative maps (for mouse vs. other mammals), as well as genome-wide comparative maps for mouse vs. human or rat.

CONCLUSION. Users have the ability to search and retrieve specific data types, sort search results, and print reports. MGD data are updated daily. MGD continues to evolve, expanding its data coverage, providing new data manipulation and display tools as well as promoting data integration with other scientific resources to meet the growing needs of the scientific community. 
ACKNOWLEDGMENT. This work was supported by National Institutes of Health Grant HG00330.

\section{REFERENCES}

1. Blake, J.A., Eppig, J.T., Richardson, J.E., Bult, C.J., Kadin, J.A., and the Mouse Genome Database Group (2001) Nucl. Acids Res. 29, 91-94.

2. Blake, J.A., Eppig, J.T., Richardson, J.E., Davisson, M.T., and the Mouse Genome Database Group (2000) Nucl. Acids Res. 28, 108-111.

3. Eppig, J.T., Blake, J.A., Davisson, M.T., Kadin, J.A., Richardson, J.E., and the Mouse Genome Database Group (2000) Lab Anim. 29, 39-43.

4. Davisson, M.T., Bradt, D.W., Merriam, J.J., Rockwood, S.F., and Eppig, J.T. (1999) The Mouse Gene Map. ILAR J. 39, 96-131. 

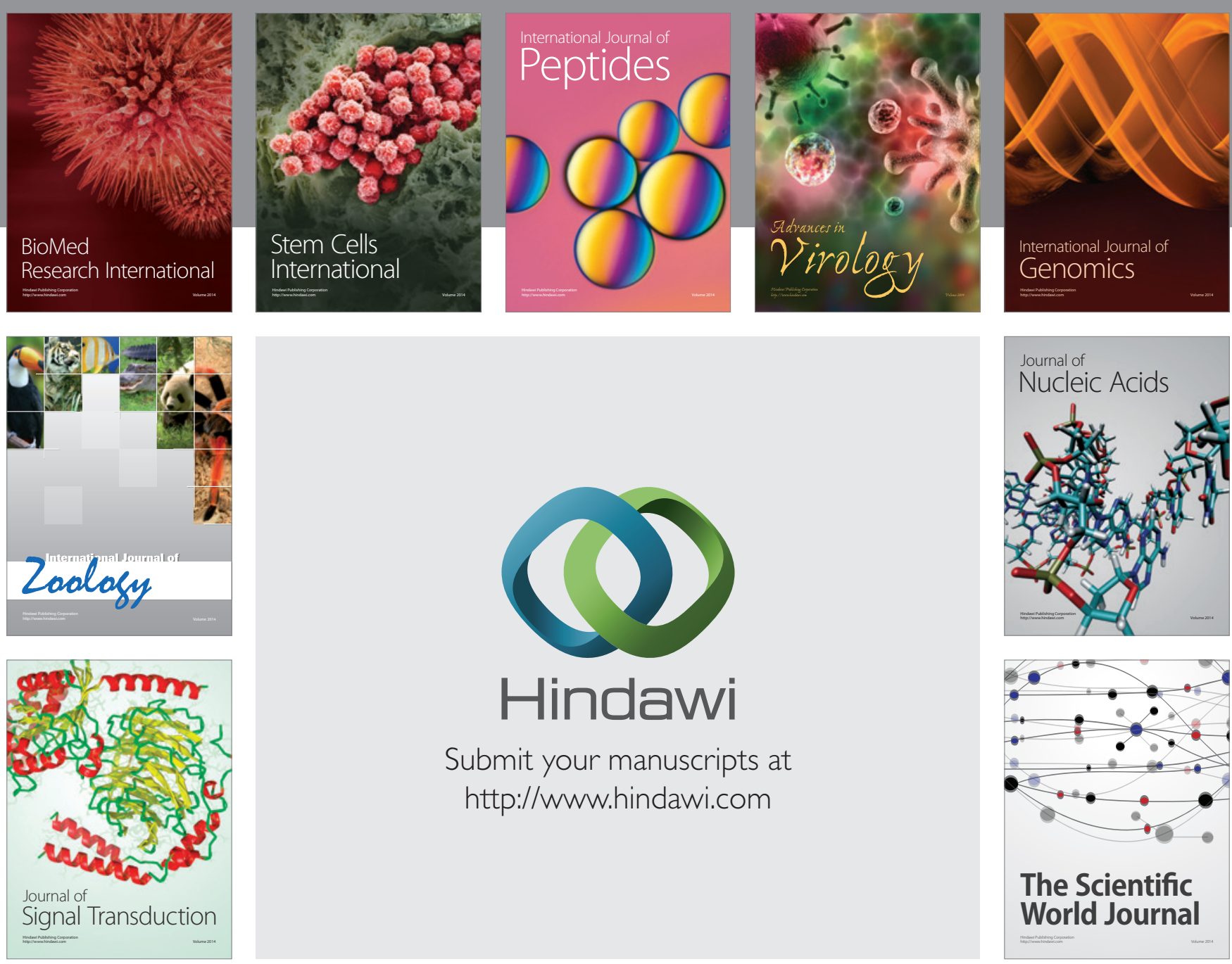

Submit your manuscripts at

http://www.hindawi.com
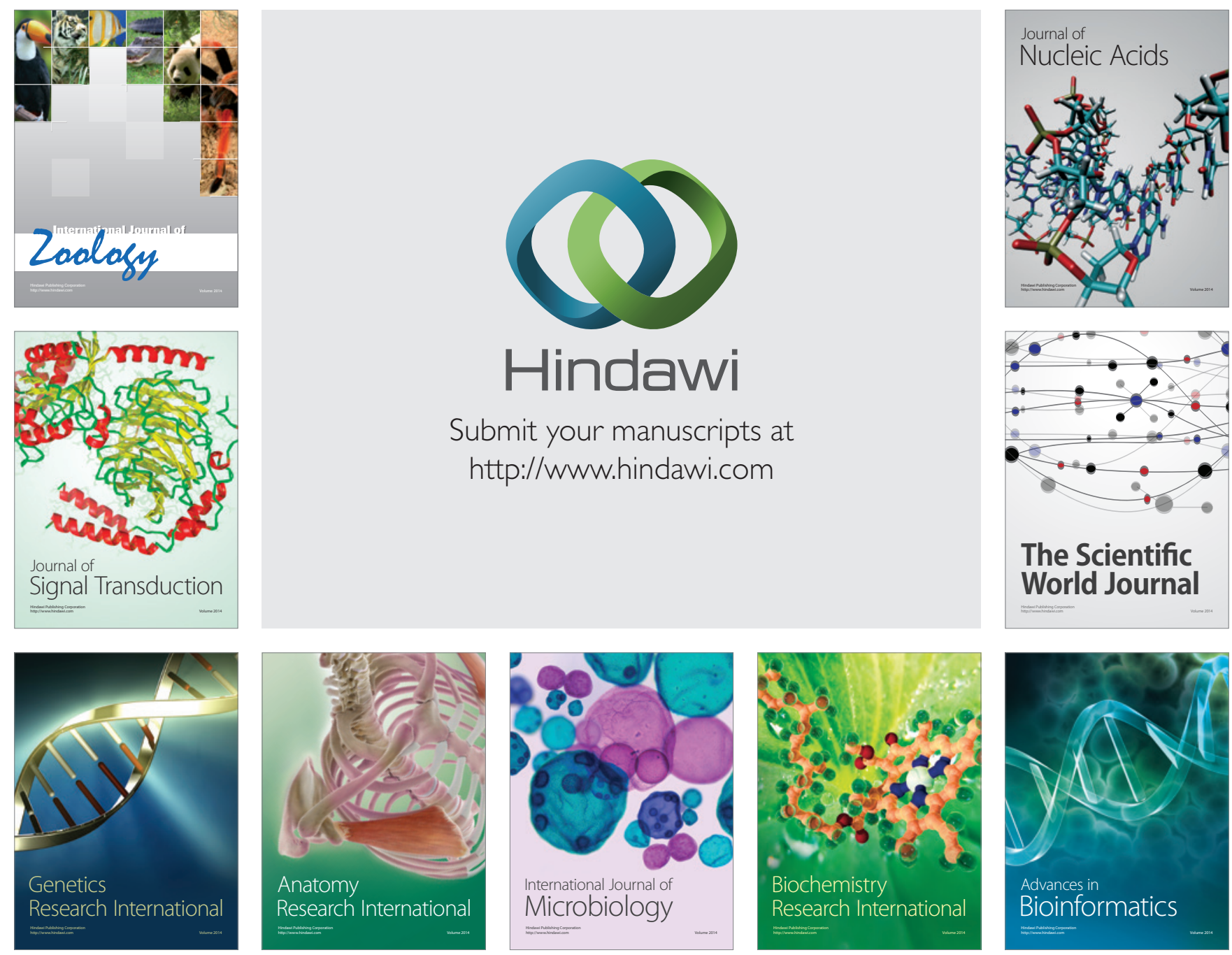

The Scientific World Journal
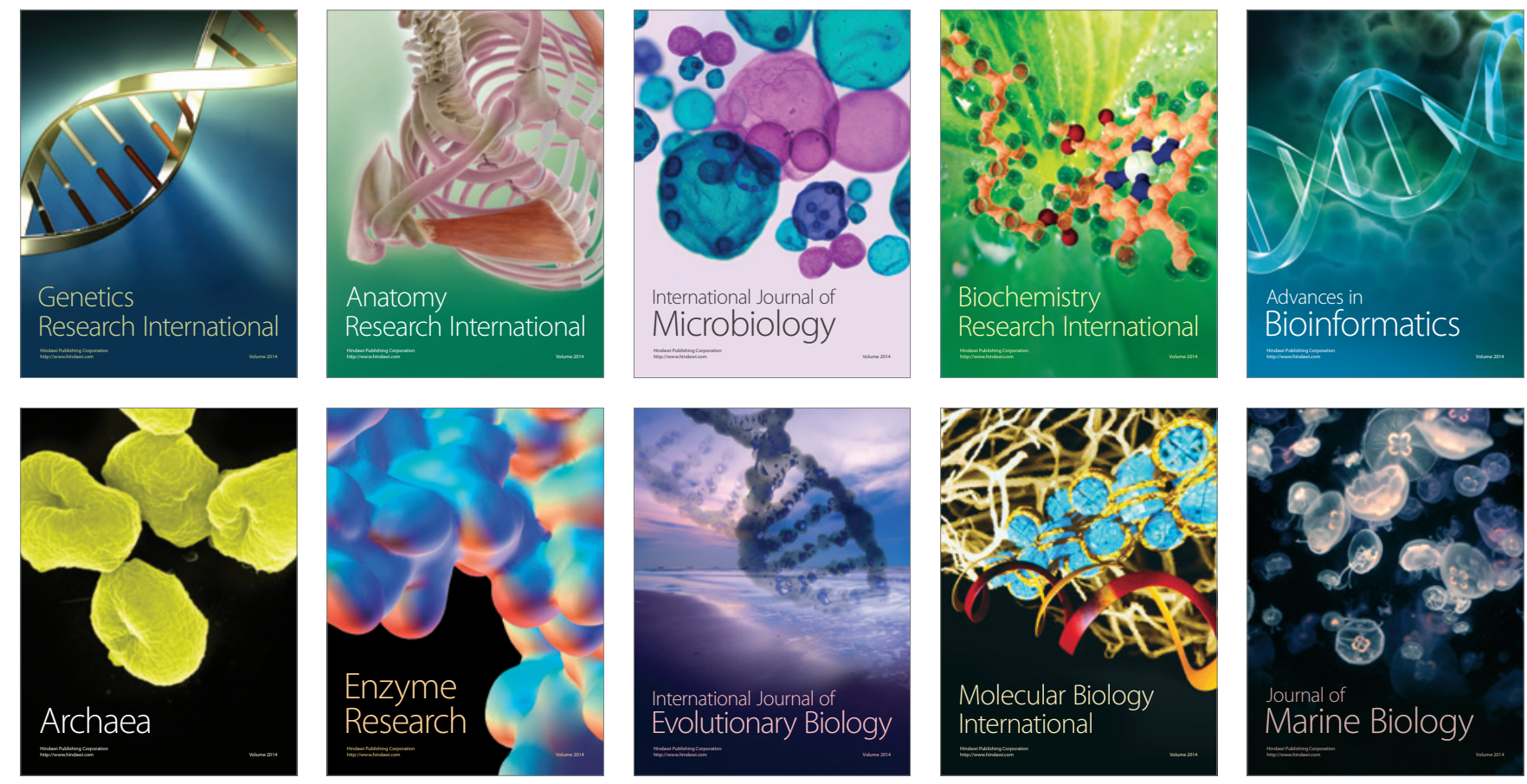